\title{
PELATIHAN PEMBUATAN BAHAN AJAR BERBASIS TEKNOLOGI INFORMASI DENGAN CAMTASIA STUDIO BAGI GURU DI SMK MUHAMMADIYAH 2 MUNTILAN - MAGELANG
}

\author{
Muhammad Sholeh $^{1}$, Suraya ${ }^{2}$, Ign. Suraya ${ }^{3}$ \\ ${ }^{1,2}$ Teknik Informatika - Fakultas Teknologi Industri \\ ${ }^{3}$ Sistem Komputer - Fakultas Sain Terapan \\ Institut Sains \& Teknologi AKPRIND Yogyakarta \\ Email : muhash@akprind.ac.id
}

\begin{abstract}
Teaching materials as one of the media that teachers can use to explain the material to the students. In the era of the development of information technology today, teachers must develop teaching materials that utilize information technology. With the support of information technology, materials or teaching materials that are packaged can be displayed more interesting and interactive. Many applications that teachers can use in creating teaching materials. One of them is Camtasia Studies. With this application, teachers do not need a programming understanding in the development of teaching materials. This application developed video-based and can be equipped with more attractive appearance. As an effort to improve the role of teachers in developing teaching materials, in SMK Muhammadiyah 2 Muntilan has been held training to create teaching materials with Camtasia Studio application. The results of training to produce teaching materials and ready to be given to students either through flash disk or uploaded in elearning school.
\end{abstract}

Keywords: Information technology, teachers, Camtasia Studio, teaching materials

\begin{abstract}
Abstrak. Bahan ajar sebagai salah satu media yang dapat digunakan guru untuk menjelaskan materi kepada para siswa. Di era perkembangan teknologi informasi saat ini, guru harus mengembangkan bahan ajar yang memanfaatkan teknologi informasi. Dengan dukungan teknologi informasi, materi atau bahan ajar yang dikemas dapat ditampilkan lebih menarik dan interaktif. Banyak aplikasi yang dapat digunakan guru dalam membuat bahan ajar. Salah satu nya adalah Camtasia Studi. Dengan aplikasi ini, guru tidak memerlukan pemahaman pemrograman dalam pengembangan kan bahan ajar. Aplikasi ini dikembangkan berbasis video dan dapat dilengkapi dengan tampilan-tampilan yang lebih menarik. Sebagai upaya meningkatkan peran guru dalam mengembangkan bahan ajar, di SMK Muhammadiyah 2 Muntilan telah diselenggarakan pelatihan membuat bahan ajar dengan aplikasi Camtasia Studio. Hasil pelatihan menghasilkan bahan ajar dan siap untuk diberikan ke siswa baik melalui flash disk maupun di unggah di elearning sekolah.
\end{abstract}

Kata kunci : Teknologi informasi, guru, Camtasia Studio, bahan ajar

\section{PENDAHULUAN}

Di era perkembangan teknologi informasi yang sangat pesat saat ini, dunia pendidikan merupakan salah satu institusi yang harus mengikuti perkembangan tersebut. Demikian juga para guru juga harus mulai menggunakan teknologi informasi dan komunikasi (TIK) dalam berinteraksi dengan siswa baik dalam pembuatan bahan ajar maupun dalam proses komunikasi dengan siswa. Bahan ajar berbasis TIK mempunyai kelebihan dibanding dengan bahan ajar berupa buku teks. Dalam proses belajar mengajar (PBM), guru tidak hanya mengajarkan materi di kelas tetapi juga harus didukung materi yang dapat dipelajari di luar kelas.

PBM yang hanya mengandalkan di kelas tentunya banyak kelemahan, diantara guru harus selalu menuliskan materi yang disampaikan, siswa harus mencatat, kesulitan dalam memperagakan materi yang berupa gambar atau simulasi. Agar masalah tersebut dapat diminimalkan, penggunaan TIK dalam proses PBM menjadi unsur yang sangat penting di era sekarang ini. Dengan bantuan TIK, proses peragaan atau simulasi dapat disampaikan dengan 
mudah dan lebih interaktif. Terdapat sejumlah alasan, mengapa guru perlu untuk mengembangkan bahan ajar, yakni antara lain; ketersediaan bahan sesuai tuntutan kurikulum, karakteristik sasaran, dan tuntutan pemecahan masalah belajar. Pengembangan bahan ajar harus memperhatikan tuntutan kurikulum, artinya bahan belajar yang akan dikembangkan harus sesuai dengan kurikulum.

Bahan ajar merupakan bagian penting dalam pelaksanaan pendidikan di sekolah. Melalui bahan ajar guru akan lebih mudah dalam melaksanakan pembelajaran dan siswa akan lebih terbantu dan mudah dalam belajar. Bahan ajar dapat dibuat dalam berbagai bentuk sesuai dengan kebutuhan dan karakteristik materi ajar yang akan disajikan. Dalam pembuatan bahan ajar ada beberapa persyaratan yang harus dipenuhi diantaranya : (Anonim, 2008)

a. Petunjuk belajar (Petunjuk siswa/guru)

b. Kompetensi yang akan dicapai

c. Content atau isi materi pembelajaran

d. Informasi pendukung

e. Latihan-latihan

f. Petunjuk kerja, dapat berupa Lembar Kerja (LK)

g. Evaluasi

h. Respon atau balikkan terhadap hasil evaluasi
Berdasarkan teknologi yang digunakan, Direktorat Pembinaan Sekolah Menengah Atas (Anonim, 2008) mengelompokkan bahan ajar menjadi empat kategori, yaitu bahan ajar cetak (printed) antara lain handout, buku, modul, lembar kegiatan siswa, brosur, leaflet, wallchart, foto/gambar, dan model/maket. Bahan ajar dengar (audio) antara lain kaset, radio, piringan hitam, dan compact disk audio. Bahan ajar pandang dengar ( audio visual) seperti video compact disk, dan film. Bahan ajar multimedia interaktif (interactive teaching material) seperti CAI (Computer Assisted Instruction), compact disk (CD) multimedia pembelajaran interaktif dan bahan ajar berbasis web (web based learning material).

Dengan menggunakan TIK, bahan ajar yang dibuat mempunyai nilai lebih. Dibanding bahan ajar kertas, bahan ajar yang dikembangkan dengan TIK mempunyai nilai lebih dengan adanya suara, gambar atau animasi serta simulasi. Penggunaan multimedia dalam pengembangan bahan ajar menjadikan bahan ajar lebih menarik dan interaktif. Dalam pemanfaatan TIK, siswa dan guru dapat menggunakan fasilitas bahan ajar yang sudah dikembangkan Kementerian Pendidikan dan Kebudayaan. Materi bahan ajar berbasis TIK dapat diunduh di laman http://medukasi.kemdikbud.go.id/medukasi/. Gambar 1 merupakan tampilan halaman depan dari website http://m-edukasi.kemdikbud.go.id/medukasi/

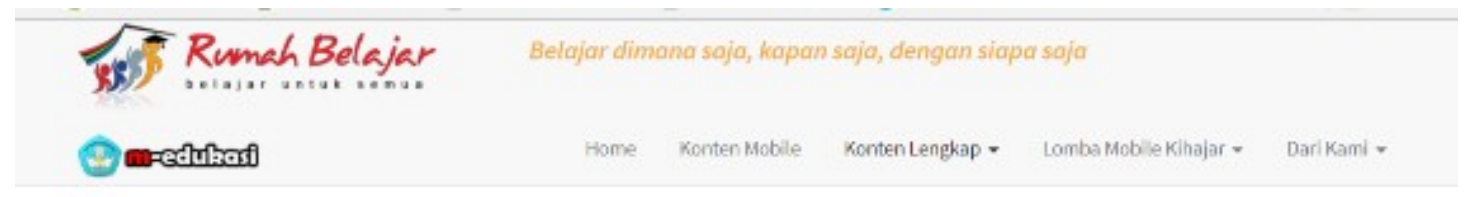

Kementerian Pendidikan dan Kebudayaan

Balai Pengembargan Multimedia Penditisan dan Ketudayar.

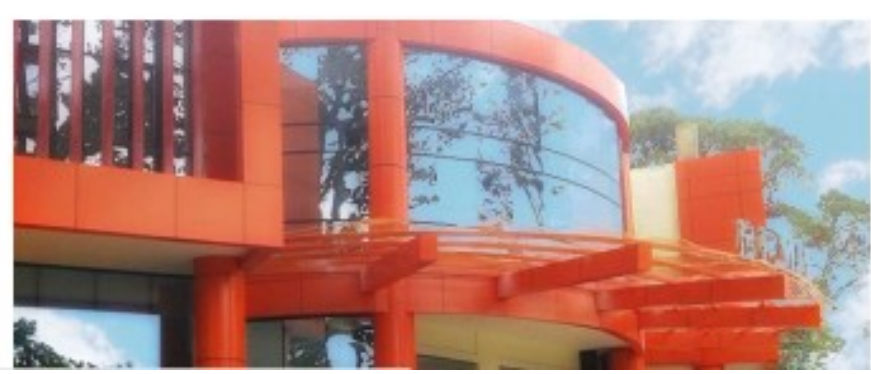

\section{BPMPK-KEMDIKBUD}

Jl. Mr. Koessactiyeno Tjandro Wiaswe, Kel. Pakintelan, Kec. Gunungpat, secuaravo 50227

Telepon : 024-8314292; Fax: 024-831005 Email : bomultimediackemdikbud sa.it

Gambar 1 Halaman depan http://m-edukasi.kemdikbud.go.id/medukasi/ 
Dalam laman ini, baik siswa maupun guru dapat melakukan proses pengunduhan dan dapat digunakan sebagai media pembelajaran. Gambar 2 contoh bahan ajar yang bisa digunakan. Disamping menggunakan bahan ajar berbasis TIK yang dapat diperoleh di http://medukasi.kemdikbud.go.id/medukasi/ atau di laman yang lain, guru semestinya juga sudah mampu membuat dan mengembangkan bahan ajar secara mandiri. Dengan kemampuan mengembangkan bahan ajar berbasis TIK secara mandiri, isi atau konten dari bahan ajar bisa disesuaikan dengan kondisi sekolah dan strategi guru dalam penyampaian materi

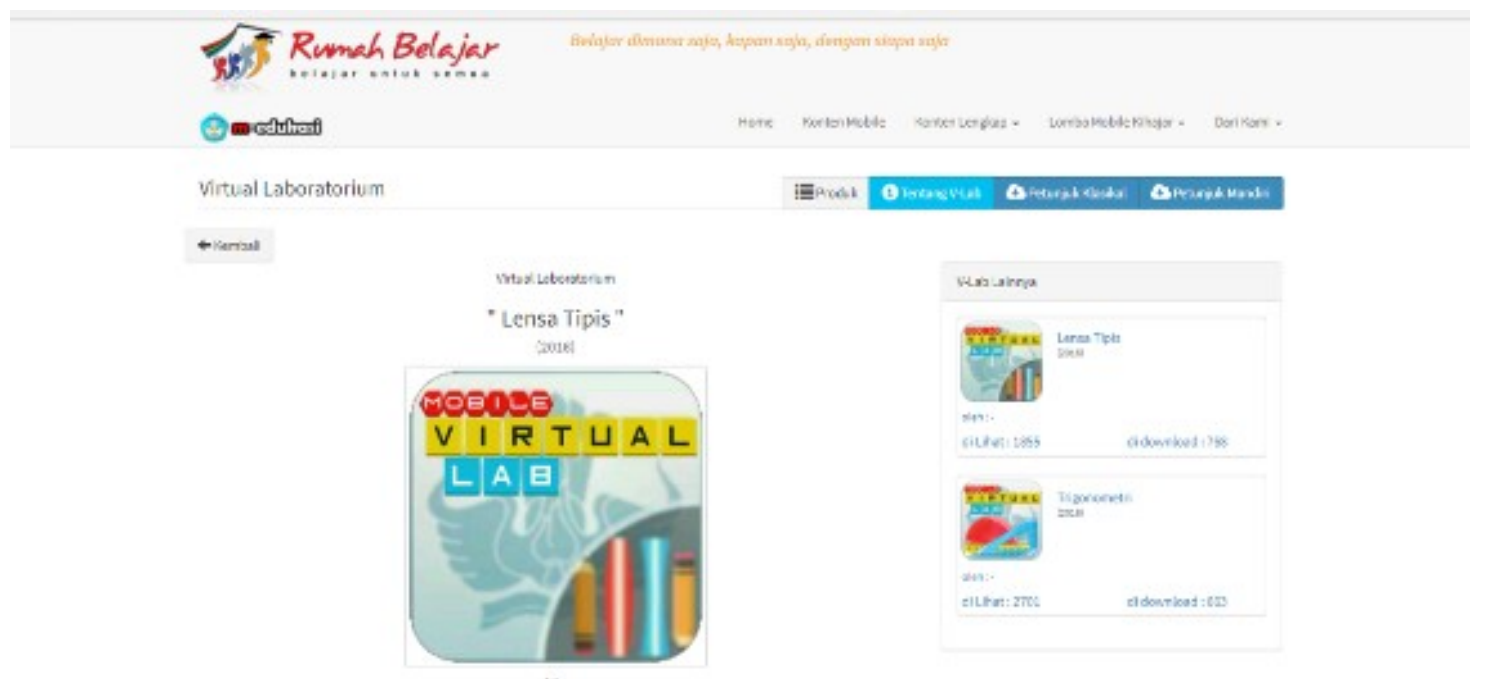

\section{Gambar 2. Materi bahan ajar yang bisa diunduh}

Beberapa hasil penelusuran pustaka yang berkaitan dengan pengembangan bahan ajar berbasis TIK diantaranya

Penelitian Latif (2013) yang dilakukan menghasilkan bahan ajar berbasis video. Pembuatan bahan ajar menggunakan aplikasi Camtasia. Aplikasi ini digunakan untuk membuat video yang menampilkan proses pembelajaran agar mudah dipahami oleh siswa dan dapat memberikan petunjuk dalam latihan soal pemecahan masalah. Sehingga siswa dapat memahami langkah-langkah menjawab latihan soal serta dapat melihat berulang-ulang jika belum memahami materi.

Maidani (Maidani, 2016), menggunakan aplikasi Camtasia untuk membuat bahan ajar. Media Camtasia studio berbantuan handout merupakan salah satu sumber belajar yang dapat digunakan oleh siswa sebagai pengganti buku ajar. Penelitian ini bertujuan untuk mengetahui pemahaman konsep siswa yang memanfaatkan media Camtasia studio berbantuan handout dengan pembelajaran konvensional pada materi sistem ekskresi. Berdasarkan hasil penelitian yang dilakukan, disimpulkan bahwa penggunaan media Camtasia studio yang dilengkapi handout secara signifikan terdapat peningkatan pemahaman konsep siswa pada materi sistem ekskresi.

(Norma Dewi Shalikhah, 2017)Pemanfaatan teknologi informasi dan komunikasi dalam dunia pendidikan merupakan satu terobosan yang luar biasa. Dukungan TIK ini diharapkan dapat

menjadi suatu inovasi dalam pembelajaran dengan banyak melibatkan komponen-komponen teknologi informasi di dalamnya. Oleh karena itu dalam era globalisasi, sektor pendidikan pun tak luput dari jangkauan nya, yaitu dengan melibatkan teknologi didalamnya dapat menghasilkan suatu sistem pendidikan. Dalam tulisan ini dibahas mengenai media pembelajaran interaktif yang melibatkan teknologi pendidikan dengan memanfaatkan aplikasi lectora inspire.

(Helmi, 2016), hasil dari studi kasus sebagai penelitian dan berdasar pada hasil wawancara terhadap guru biologi di lima sekolah menengah atas (SMA) di kota Bogor menunjukkan masih sangat diperlukan bahan ajar yang baik bagi pembelajaran biologi, terutama bahan ajar pada materi evolusi yang menarik bagi pembelajaran. Dengan adanya bahan ajar yang 
baik serta menarik berbantuan aplikasi Camtasia berbentuk kumpulan video materi evolusi maka akan dapat memberikan kontribusi nyata bagi pembelajaran biologi terkhusus materi Evolusi di sekolah menengah atas (SMA) di Kota Bogor.

\section{METODE PELAKSANAAN}

Pelatihan pengembangan bahan ajar dengan Camtasia Studi dilaksanakan di SMK Muhammadiyah 2 Muntilan dan diikuti 30 guru. Sebelum memberikan pelatihan dilakukan penjajagan sejauh mana para guru di SMK Muhammadiyah 2 Muntilan sudah menggunakan TIK dalam PBM. Penggunaan TIK masih banyak didominasi penggunaan Microsoft Power Point dan penggunaan Camtasia Studi belum ada yang menggunakan.

\section{Peralatan yang diperlukan}

Microsoft Windows XP, Windows Vista, Windows 7, or Windows 8

- Microsoft DirectX 9 or later version
- $\quad$ Microsoft .NET 4.0 Client Profile

- Dual-core processor minimum 2 GB RAM minimum $\sim$ Rekomendasi: $4 \mathrm{~GB}$ atau lebih

- 2 GB ruang hard disk untuk instalasi

- Display dimensions of $1024 \times 768$ atau lebih

- Dedicated Windows-compatible sound card, microphone and speakers

\section{Instalasi Camtasia Studio}

Camtasia Studio merupakan software yang dikembangkan oleh Tech Smith Corporation khusus bidang multimedia. Camtasia dikemas untuk recording, editing, dan publishing dalam membuat video presentasi yang ada pada layar (screen) komputer (Adi, 2014). Software Camtasia Studio dapat di unduh di https://signin.techsmith.com (Gambar 3) . Software yang diunduh masih berupa trial selama 30 hari dan hasil dari instalasi menampilkan antar muka yang digunakan untuk memulai pembuatan bahan ajar. Hasil tampilan awal Camtasia Studi dapat dilihat pada gambar 4 .

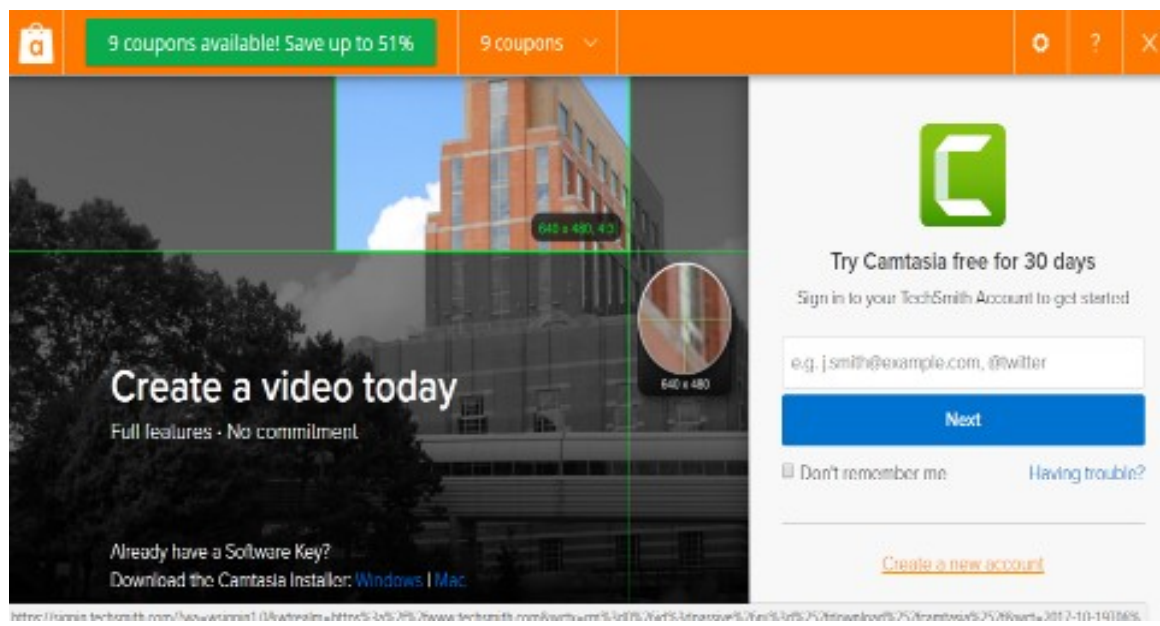

Gambar 3 Laman https://signin.techsmith.com.

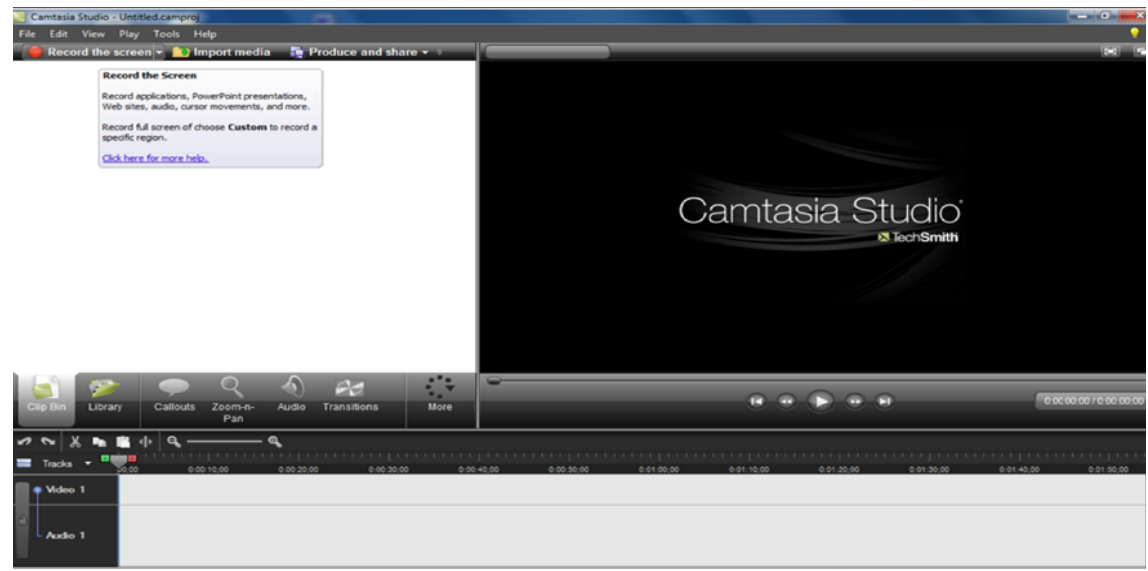

Gambar 4 Tampilan awal Camtasia Studio 
HASIL DAN PEMBAHASAN

Proses Pelatihan

Dalam pelatihan ini, disamping melakukan pendampingan bagaimana menggunakan Camtasia Studi juga diberikan strategi dalam membuat bahan ajar. Penekanan pertama dalam pelatihan adalah memberikan penjelasan menggunakan Camtasia Studio sehingga para guru memahami dan proses serta pembuatan bahan ajar. Gambar 5-10, menggambarkan proses pelaksanaan pelatihan

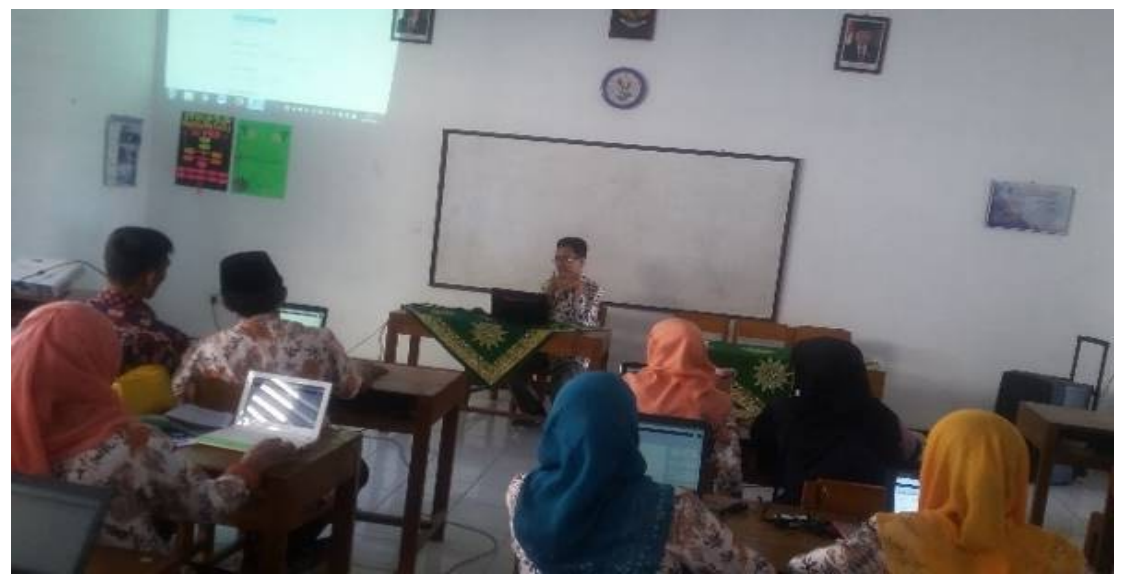

Gambar 5. Penjelasan Materi

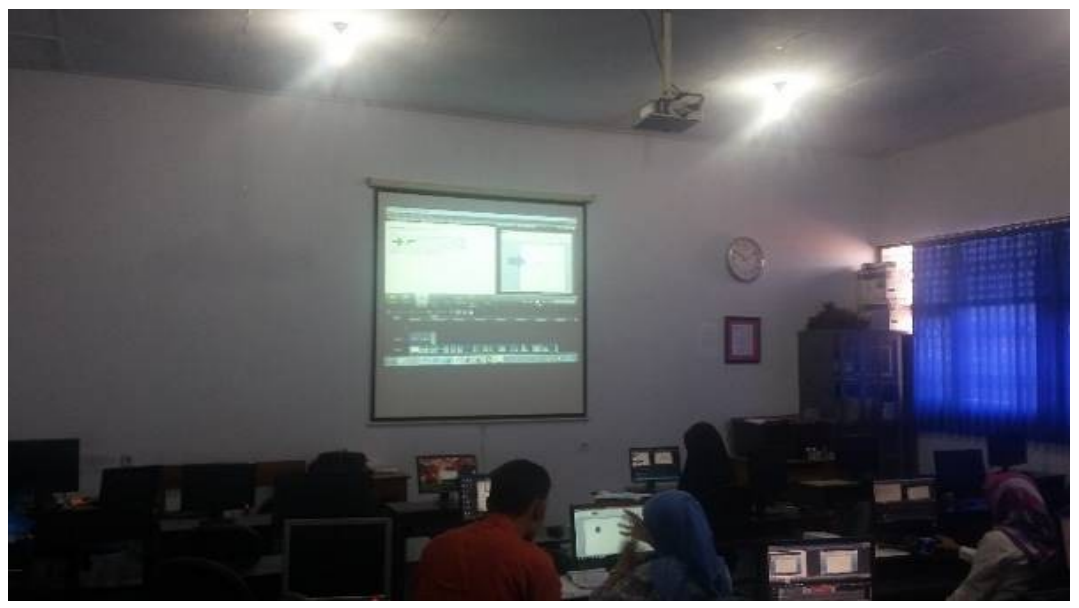

Gambar 6. Penjelasan Camtasia Studio

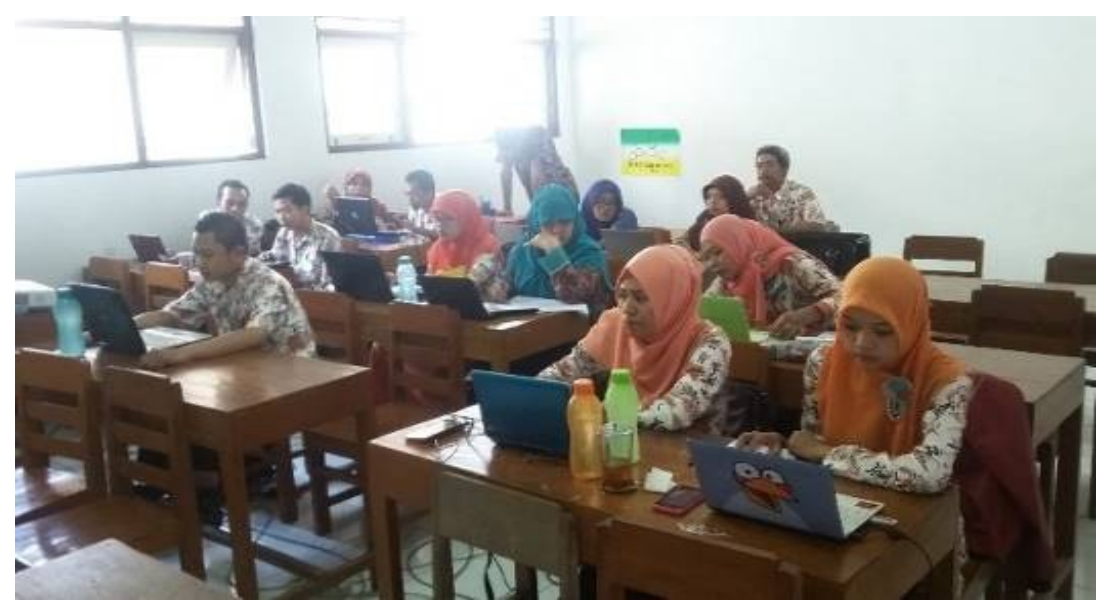

Gambar 7. Pelaksanaan Pelatihan 


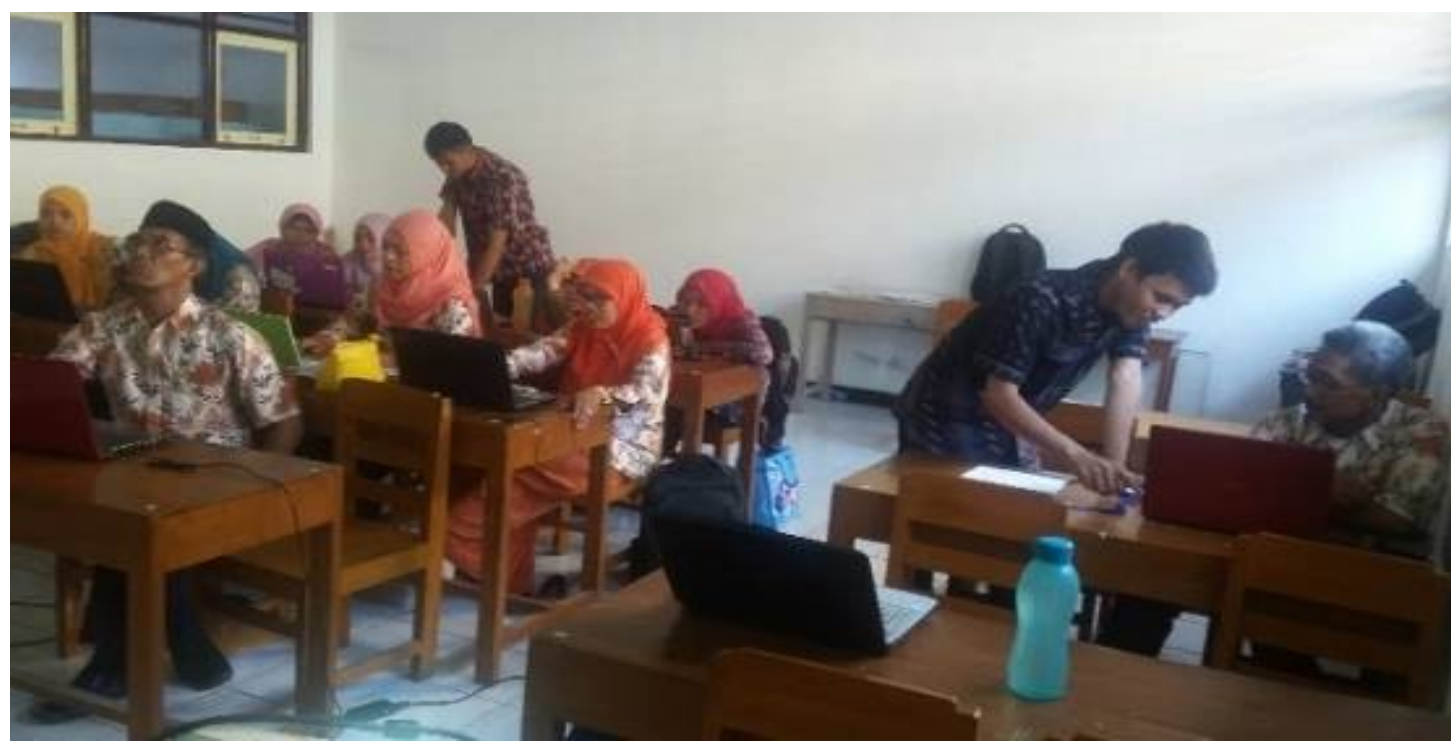

Gambar 8 Pendampingan Pelatihan

\section{Materi pelatihan}

- Proses install Camtasia Studio

- Menjalankan Camtasia Studio

- Membuat project baru (bahan ajar)

- Mengenal menu-menu Camtasia Studio

- Membuat rekaman (membuat rekaman dengan file Microsoft Power Point

- Membuat halaman judul

- Menyisipkan Watermark

- Menyisipkan efek transisi

- Menambahkan callout

- Produksi dan distribusi hasil rekaman

\section{Hasil Pelatihan}

Tahapan pelatihan bahan ajar multimedia dilakukan dalam tahapan :

1. Penjelasan materi Camtasia Studio

- Tahapan praktik membuat bahan ajar Menentukan Isi Halaman Depan

Isi halaman depan hendaknya memuat beberapa hal berikut yaitu : Judul Bahan Ajar, Nama Pemateri dan Identitas Institusi.

- Membuat Outline
Membuat daftar/list konten materi yang akan disampaikan atau dimasukkan ke dalam bahan ajar multimedia. Outline ini dipresentasikan ke dalam bentuk pointpoint. Dalam setiap point tersebut diinventarisir pila materi yang akan ditampilkan seperti teks, gambar, video, audio, animasi dan narasinya.

- Membuat Sketsa Tampilan

- Mengumpulkan Bahan Baku

Setelah semua rancangan baik dalam bentuk outline maupun sketsa tampilan jadi, maka yang harus dilakukan berikutnya adalah mengumpulkan semua bahan baku (berupa media) yang dipakai.

2. Tahapan Produksi

Setelah diberikan materi pelatihan menggunakan Camtasia Studio, langkah selanjutnya adalah membuat bahan ajar. Dalam pelatihan ini, para guru mendapatkan tugas untuk membuat bahan ajar sesuai dengan mata pelajaran yang diampu. Hasil bahan ajar ada pada gambar 9-12 


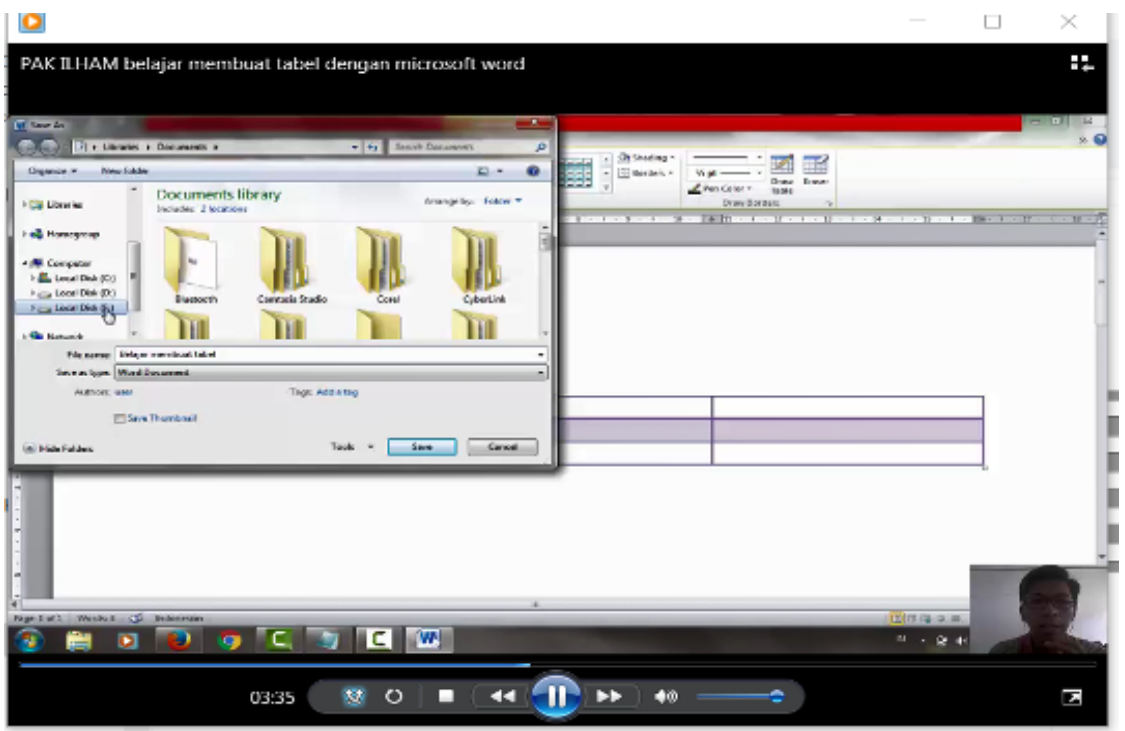

Gambar 9 Bahan Ajar Belajar Microsoft Word

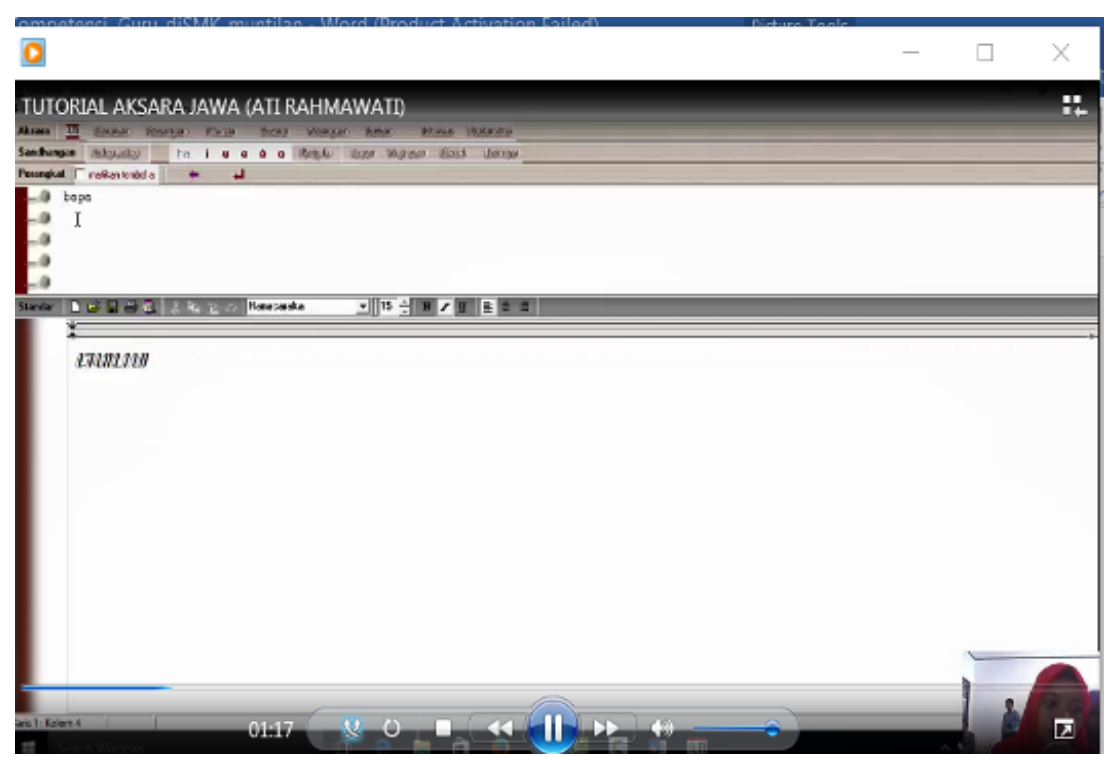

Gambar 10 Bahan Ajar Belajar Aksara Jawa

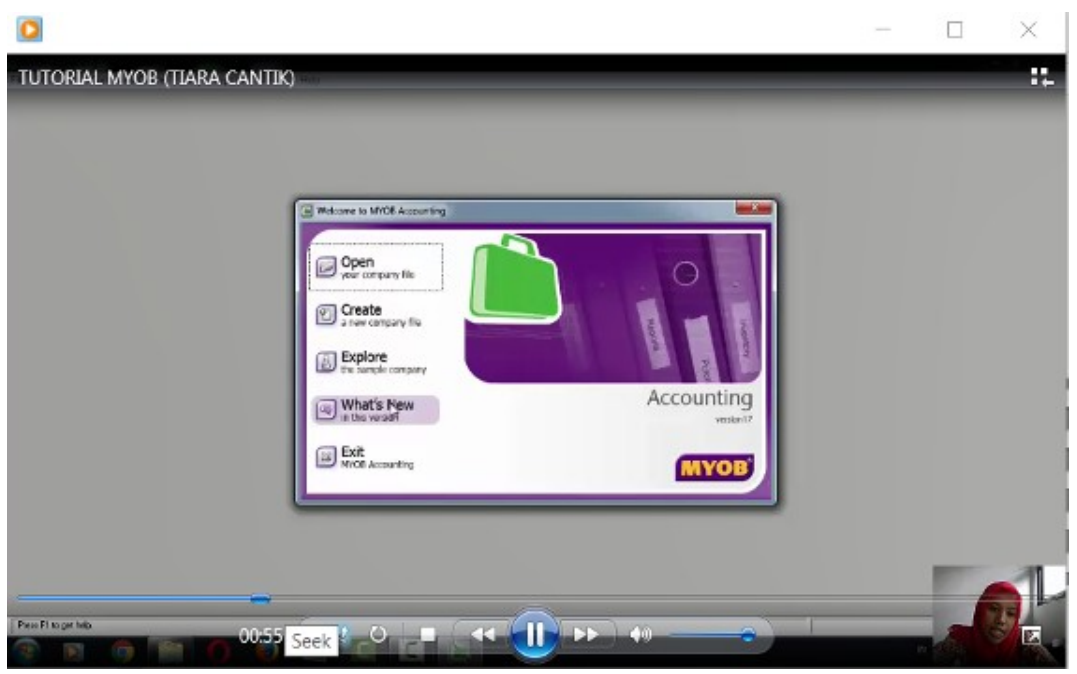

Gambar 11 Bahan Ajar Belajar MYOB 


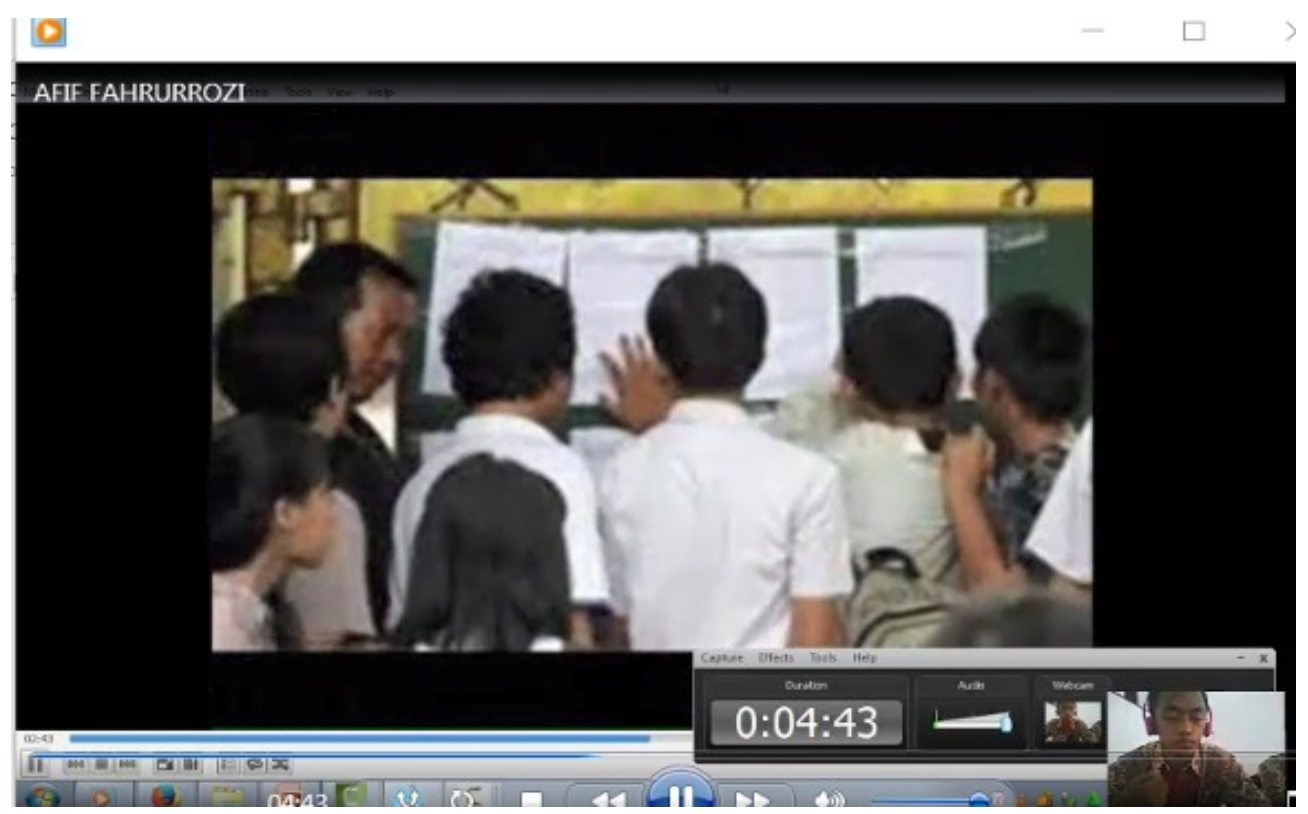

\section{Gambar 12 Bahan Ajar Belajar IPS}

\section{SIMPULAN}

Aplikasi Camtasia Studio dapat digunakan sebagai sarana membuat bahan ajar berbasis TIK. Aplikasi ini digunakan untuk membuat bagah ajar berbasis video dan hasil video dapat dilengkapi dengan callout yang menjelaskan materi yang dibahas. Penggunaan aplikasi ini tidak sulit dan tidak ada pemrograman sehingga para guru dapat lebih kreatif dalam pengembangkan bahan ajar.

Hasil pelatihan di SMK Muhammadiyah 2 Muntilan menghasilkan bahan ajar berbasis video dan diharapkan hasil video ini selalu diperbaharui dan didistribusikan ke siswa. Dengan bahan ajar berbasis video ini dapat menjadi salah satu cara belajar siswa diluar pembahasan mataeri di kelas.

\section{DAFTAR PUSTAKA}

Adi, A. P., 2014. Menjadi Pembuat Film Andal dengan Camtasia Studio 8. Jakarta : Elex Media Komputindo.

Anonim, 2008. Pedoman Pengembangan Bahan Ajar. Jakarta: Departemen Pendidikan Nasional.

Helmi, 2016. Pengembangan Bahan Ajar Evolusi Berbantuan Aplikasi Camtasia Studio 8
Sebagai Sarana Pembelajaran IPA Biologi SMA. MANGIFERA EDU, 1(1), pp. 31-37.

Latif, Y., Darmawijoyo \& Putri, R. I. I., 2013. Pengembangan Bahan Ajar Berbantuan Camtasia pada Pokok Bahasan Lingkaran melalui Edmodo untuk siswa MTs. JURNAL KREANO, ISSN , 4(2), pp. 105114.

Maidani, D. M., Khairil \& Rahmatan, H., 2016. Penggunaan Media Camtasia Studio Berbantuan Handout untuk Meningkatkan Pemahaman Konsep Siswa Pada Konsep Sistem Ekskresi di SMA Negeri 12 Banda Aceh. Jurnal Biotik, 4(1), pp. 75-80.

Norma Dewi Shalikhah, A. P. M. S. I., 2017. Media Pembelajaran Interaktif Lectora Inspire sebagai Inovasi Pembelajaran. WARTA LPM , 20(1), pp. 9-16. 